\section{BRAZIULIAN JOURNAL \\ OF MEDICAL AND BIOLOGICAL RESHARCH}

www.bjournal.com.br
ISSN 0100-879X

Volume 42 (12) 1119-1247 December 2009

BIOMEDICAL SCIENCES

AND

CLINICAL INVESTIGATION

Braz J Med Biol Res, December 2009, Volume 42(12) 1156-1162

Tracheal cryopreservation: caspase-3 immunoreactivity in tracheal epithelium and in mixed glands

A. Sotres-Vega, M. Baltazares-Lipp, J. Villalba-Caloca, M.O. Gaxiola-Gaxiola, J.A. SantibañezSalgado, J.R. Olmos-Zúñiga and R. Jasso-Victoria

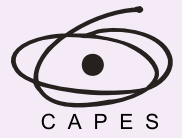




\title{
Tracheal cryopreservation: caspase-3 immunoreactivity in tracheal epithelium and in mixed glands
}

\author{
A. Sotres-Vega ${ }^{1,2}$, M. Baltazares-Lipp ${ }^{1}$, J. Villalba-Caloca ${ }^{1}$, M.O. Gaxiola-Gaxiola ${ }^{1}$, \\ J.A. Santibañez-Salgado ${ }^{1}$, J.R. Olmos-Zúñiga ${ }^{1}$ and R. Jasso-Victoria ${ }^{1}$ \\ ${ }^{1}$ Department of Experimental Surgery Research, \\ National Institute of Respiratory Diseases "Ismael Cosio Villegas", Mexico City, Mexico \\ 2Doctoral Program in Biological Sciences, \\ Autonomous Metropolitan University-Xochimilco, Mexico City, Mexico
}

\begin{abstract}
Cryopreservation has an immunomodulating effect on tracheal tissue as a result of class II antigen depletion due to epithelium exfoliation. However, not all epithelium is detached. We evaluated the role of apoptosis in the remaining epithelium of 30 cryopreserved tracheal grafts. Caspase-3 immunoreactivity of tracheal epithelium was studied in canine tracheal segments cryopreserved with $\mathrm{F} 12 \mathrm{~K}$ medium, with or without subsequent storage in liquid nitrogen at $-196^{\circ} \mathrm{C}$ for 15 days. Loss of structural integrity of tracheal mixed glands was observed in all cryopreserved tracheal segments. Caspase-3 immunoreactivity in tracheal mucosa and in mixed glands was significantly decreased, in contrast to the control group and to cryopreserved tracheal segments in which it remained high, due to the effect of storage in liquid nitrogen ( $P<0.05$, ANOVA and Tukey test). We conclude that apoptosis can be triggered in epithelial cells during tracheal graft harvesting even prior to cryopreservation, and although the epithelial caspase-3 immunoreactivity is reduced in tracheal cryopreservation, this could be explained by increased cell death. Apoptosis cannot be stopped during tracheal cryopreservation.
\end{abstract}

Key words: Tracheal cryopreservation; Epithelium; Caspase-3

\section{Introduction}

To date, there are no definitive clinical surgical strategies to repair tracheal defects longer than $7 \mathrm{~cm}$, despite the fact that experimental tracheal transplants and synthetic or biological prostheses have been used to repair lesions (1-5).

Different experimental reconstruction models have been prepared with cryopreserved tracheal grafts frozen in cellular culture media (6). Based on freezing temperature and liquid nitrogen storage, cryopreserved tracheal graft protocols can be divided into two types: a) tracheal grafts frozen at $-60^{\circ}$ to $-140^{\circ} \mathrm{C}$ and stored in liquid nitrogen until their use in surgical repair (7-20), and b) tracheal grafts cryopreserved within a more homogeneous range of temperature $\left(-80^{\circ} /-85^{\circ} \mathrm{C}\right)$, without liquid nitrogen storage $(3,21-24)$.

The results obtained for experimental tracheal reconstruction with cryopreserved grafts are contradictory, and therefore this material has not been considered for clinical application. Most investigators agree that cryopreservation has an immunomodulating effect on tracheal allografts since it decreases antigenicity $(5-7,12-$ $14,25-28)$. This is attributed to the depletion of class II leukocyte antigen expression due to the exfoliation of tracheal epithelium produced during the freezing and defrosting process $(3,5,6,11,28,29)$.

The freezing and thawing process results in decreased cell viability, although remaining intact and viable tracheal epithelial cells can be found even after cryopreservation. These living cells can induce an immunological reaction in the host. Since caspase-3 is the common denominator in both apoptotic starting pathways (30), we decided to study caspase-3 immunoreactivity in the remaining viable epithelial cells of cryopreserved tracheal segments.

Correspondence: A. Sotres-Vega, Departamento de Cirugía Experimental, Unidad de Investigación, Instituto Nacional de Enfermedades Respiratorias, Calzada de Tlalpan 4502, Col. Sección XVI, Tlalpan 14080, México, DF, Mexico.

Fax: +52-55-5487-1706. E-mail: avesotve@yahoo.com

Received May 15, 2009. Accepted October 23, 2009. Available online November 9, 2009. Published December 4, 2009. 


\section{Material and Methods}

The protocol was reviewed and approved by the Ethics Committee of the National Institute of Respiratory Diseases Ismael Cosio Villegas (NIRD), and carried out according to the technical specifications for the Care and Use of Laboratory Animals of the Official Mexican Norm (31) and the Guide for the Care and Use of Laboratory Animals prepared by the National Institutes of Health, USA (32).

\section{Surgical technique}

Four tracheas were harvested from 4 unrelated mongrel dogs weighing 15 to $30 \mathrm{~kg}$. The dogs were prepared before surgery with a 24-h fast for solid food and a 12-h fast for liquids. Initial anesthesia was induced with $0.1 \mathrm{mg} / \mathrm{kg}$ iv hydrochloric xylazine (Rompum, Bayer, Germany) and propofol $6 \mathrm{mg} /$ kg (Diprivan, Astra Zeneca, Mexico), followed by immediate intubation with an endotracheal tube (Rush, Malaysia) connected to a volume ventilator (Harvard Apparatus, USA) with a vaporizer (Isotec $3 \mathrm{Ohmeda}$ ) at a respiratory rate of 20 breaths $/ \mathrm{min}$, volume of $15 \mathrm{~mL} / \mathrm{kg}$ and $100 \% \mathrm{FiO}_{2}$. Anesthesia was maintained with $2 \%$ isoflurane. The anesthetized dog was placed in the supine position. The neck of each animal was shaved and prepared with povidone-iodine solution. The entire trachea was exposed after separating the strap muscles. After harvesting the trachea, fine dissection was done on a Mayo tray placed over an ice chest.

\section{Tracheal segment preparation}

The cricoid cartilage was removed. The trachea was cut into five ring segments, washed for $3 \mathrm{~min}$ in cold glucose solution, and kept under ice with changes of the solution every minute. The glucose solution was prepared with $50 \%$ glucose (DX-50 solution, PISA, Mexico), $20 \mathrm{~mL} 20 \%$ mannitol (PISA), and $5000 \mathrm{U}$ heparin (Inhepar, PISA), and $0.1 \mathrm{~mL}$ antibiotic-antimycotic solution (A5955, Sigma, USA) was added per liter of solution.

\section{Cryopreservation solution}

The solution used for cryopreservation of the tracheal segments was F12K (21700-026, Gibco, USA) to which 10\% dimethylsulfoxide (D2650, Sigma), 20\% fetal bovine serum (16000-044, Gibco), 20\% hyaluronic acid solution at $0.1 \%$ (53730, Fluka, Germany), and $0.1 \mathrm{~mL}$ antibioticantimycotic solution (A5955, Sigma) were added per liter of solution.

\section{Treatments of the tracheal segments}

Cryopreservation of the tracheal segments included two different treatment schemes regarding storage in liquid nitrogen. In both schemes, immediately after washing with the glucose solution, each tracheal segment was placed in a cryogenic vial containing F12K medium. The vials were then placed inside a polystyrene foam box and frozen at $-70^{\circ} \mathrm{C}$.

\section{Study groups}

Immediately after washing in glucose solution, the tracheal segments were randomly divided into a control group without cryopreservation and four groups with cryopreservation.

Group 1 ( $N=6$, control group, without cryopreservation). The tracheal segments were not exposed to any type of cryopreservation. They were only rinsed in glucose solution.

Group $2(N=6)$. The tracheal segments were cryopreserved in $\mathrm{F} 12 \mathrm{~K}$ medium at $-70^{\circ} \mathrm{C}$ for 2 days.

Group $3(N=6)$. The tracheal segments were cryopreserved in $\mathrm{F} 12 \mathrm{~K}$ medium at $-70^{\circ} \mathrm{C}$ for 2 days, followed by storage in liquid nitrogen at $-196^{\circ} \mathrm{C}$ for 15 days.

Group $4(N=6)$. The tracheal segments were cryopreserved in $\mathrm{F} 12 \mathrm{~K}$ medium at $-70^{\circ} \mathrm{C}$ for 15 days.

Group $5(N=6)$. The tracheal segments were cryopreserved in $\mathrm{F} 12 \mathrm{~K}$ medium at $-70^{\circ} \mathrm{C}$ for 15 days, followed by storage in liquid nitrogen at $-196^{\circ} \mathrm{C}$ for 15 days.

\section{Thawing the cryopreserved tracheal segments}

At the end of the cryopreservation time, the cryogenic vials were placed in a double boiler at $37^{\circ} \mathrm{C}$ for $30 \mathrm{~min}$ and immediately rinsed for 3 min in $\mathrm{F} 12 \mathrm{~K}$ medium maintained at $37^{\circ} \mathrm{C}$, with three changes of the solution.

\section{Microscopic evaluation}

The tissue samples collected from the central and external portion of the tracheal ring were embedded in paraffin blocks and fixed in $10 \%$ buffered formalin for $24 \mathrm{~h}$. They were dehydrated in increasing ethanol concentrations, cleared in xylol, embedded and blocked in paraffin wax, and then cut into $4-\mu \mathrm{m}$ thick sections with a rotatory microtome. The sections were mounted on glass slides and stained with hematoxylin and eosin and safranin $O$.

Immunoreactive caspase- 3 in the tracheal epithelium (mucosa and glands) was determined with a polyclonal antibody (caspase 3 (CPP32) Ab-4, Rabbit Polyclonal Antibody, Neo Markers, Lab Vision, RB-1197-P, USA) and the biotin-avidin-peroxidase system, after staining with aminoethylcarbazole and double staining with hematoxylin. A negative control for caspase- 3 was included in all tests.

\section{Results}

Thirty 5-ring long tracheal segments were obtained from the tracheas of 4 unrelated mongrel dogs, for a total of 90 tracheal rings. The proximal, central, and distal rings (3 rings per tracheal segment) were studied and processed for histological evaluation and for the determination of caspase-3 immunoreactivity.

\section{Microscopic evaluation}

Histologically, the cross-section of the tracheal wall in both the control and cryopreserved segments displayed 
scattered denuded epithelium, with normal structural integrity. The smooth muscle in the membranous portion of the trachea was grossly and histologically viable. The tracheal hyaline cartilage in all segments maintained their horse-shoe shape, and there was no disruption of the cartilaginous architecture (Figure 1). The cartilage showed viable chondrocyte nuclei in the lacunae (Figure 2).

Tracheal mucosa epithelium. All groups showed areas of unaltered tracheal epithelium, and different degrees of detachment ranging from mild to total tracheal epithelial cell detachment.

Tracheal mixed glands. The tracheal mixed glands of the control group showed normal structural integrity, with uncongested tracheal lumen and epithelial cells.

All the cryopreserved groups showed dilated mixed glands and depletion of structural integrity, with congested lumen and depletion of epithelial cells.

\section{Immunoreactive caspase-3}

Epithelium from tracheal mucosa. The number and percentage of tracheal rings positive for caspase-3 immunoreactivity in the epithelium from the tracheal mucosa is shown in Table 1 and is illustrated in Figure 3.

The epithelium of the tracheal mucosa contained caspase-3 in all 18 rings (100\%) from the control group. Inside every ring, there were areas with different caspase-3 immunoreactivity, which were classified as follows: 1) no caspase-3 immunoreactivity in the epithelial cells, 2) immunoreactivity in a few epithelial cells, 3) immunoreactivity found mainly in the basal epithelial cells, and 4) immunoreactivity localized in most of the epithelial cells (Figure 4). The percentage of tracheal rings with caspase- 3 immunoreactivity in the epithelium of cryopreserved tracheal segments was $55.6 \%$ for group $2,11.1 \%$ for group $3,77.8 \%$ for group 4, and $0 \%$ for group 5 .

The number of rings with caspase- 3 immunoreactivity in the epithelium from the tracheal mucosa was decreased in all the cryopreservation groups (Figure 5). This finding was statistically significant in the groups stored at $-70^{\circ} \mathrm{C}$ and in liquid nitrogen (control vs $-70^{\circ} \mathrm{C}$, control vs $-196^{\circ} \mathrm{C}$, and $-70^{\circ} \mathrm{C}$ vs $-196^{\circ} \mathrm{C} ; \mathrm{P}<0.03$, ANOVA and Tukey test)

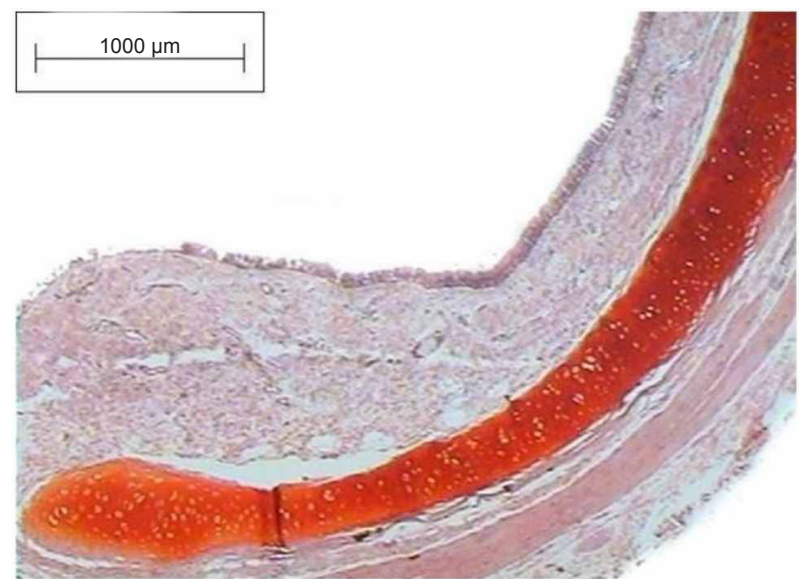

Figure 1. Cryopreserved tracheal cartilage frozen at $-70^{\circ} \mathrm{C}$, in F12K medium for 15 days, followed by liquid nitrogen storage at $-196^{\circ} \mathrm{C}$ for 15 days (group 5; Safranin O, 2.5X). Smooth muscle was histologically viable and the cartilage maintained its horseshoe shape without disruption of cartilaginous architecture.

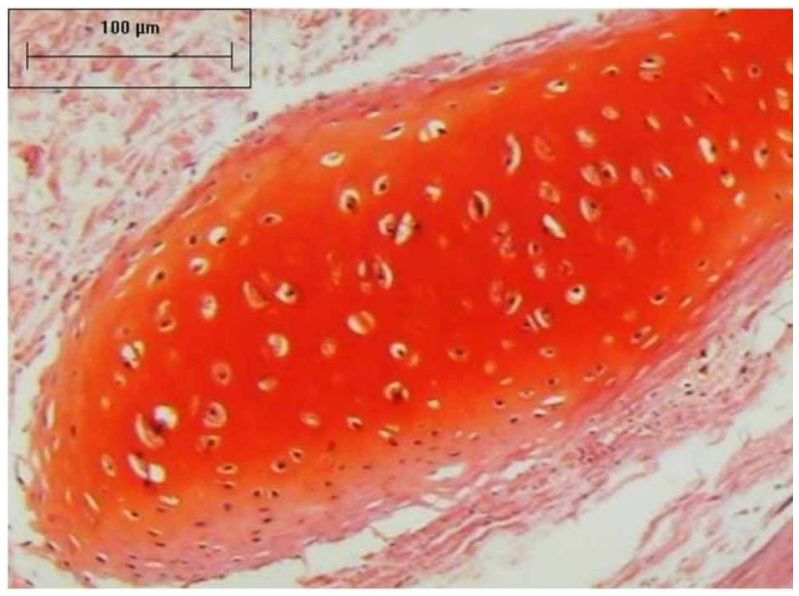

Figure 2. Cryopreserved tracheal cartilage frozen at $-70^{\circ} \mathrm{C}$, in F12K medium for 15 days, followed by liquid nitrogen storage at $-196^{\circ} \mathrm{C}$ for 15 days (group 5; Figure 1, 10X). The cartilage showed viable chondrocyte nuclei in the lacunae.

Table 1. Study groups, cryopreservation conditions, and number and percentage of tracheal rings with caspase-3 immunoreactivity in tracheal mucosa epithelium.

\begin{tabular}{ccccc}
\hline Groups & $\begin{array}{c}\text { Cryopreservation } \\
\text { time }\left(-70^{\circ} \mathrm{C}\right)\end{array}$ & $\begin{array}{c}\text { Storage in liquid } \\
\text { nitrogen (15 days) }\end{array}$ & $\begin{array}{c}\text { Rings with epithelium } \\
\text { caspase-3 immunoreactivity }\end{array}$ & $\begin{array}{c}\text { Rings without epithelium } \\
\text { caspase-3 immunoreactivity }\end{array}$ \\
\hline 1 & - & - & $18(100 \%)$ & $0(0 \%)$ \\
2 & 2 days & No & $10(55.6 \%)$ & $8(44.4 \%)$ \\
3 & 2 days & Yes & $2(11.1 \%)$ & $16(88.9 \%)$ \\
4 & 15 days & No & $14(77.8 \%)$ & $4(22.2 \%)$ \\
5 & 15 days & Yes & $0(0 \%)$ & $18(100 \%)$ \\
\hline
\end{tabular}

Data are reported as number with percent in parentheses for 18 rings. 
regardless of time of storage at $-70^{\circ} \mathrm{C}$ (control, 2 days at $-70^{\circ} \mathrm{C}$, and 15 days at $-70^{\circ} \mathrm{C}$ vs 2 days +15 days in liquid nitrogen and $v s 15$ days +15 days in liquid nitrogen; $P=$ 0.00 , ANOVA and Tukey test). No significant difference was found between the number of rings with caspase-3 immunoreactivity in the epithelium from the groups with the tracheal mucosa cryopreserved at $-70^{\circ} \mathrm{C}$ (control without cryopreservation vs 2 days and vs 15 days, $P=0.20 ; 2$ days vs 15 days, $\mathrm{P}=1.0 ; 2$ days vs 15 days (after liquid nitrogen storage), $\mathrm{P}=0.81$, ANOVA and Tukey test).

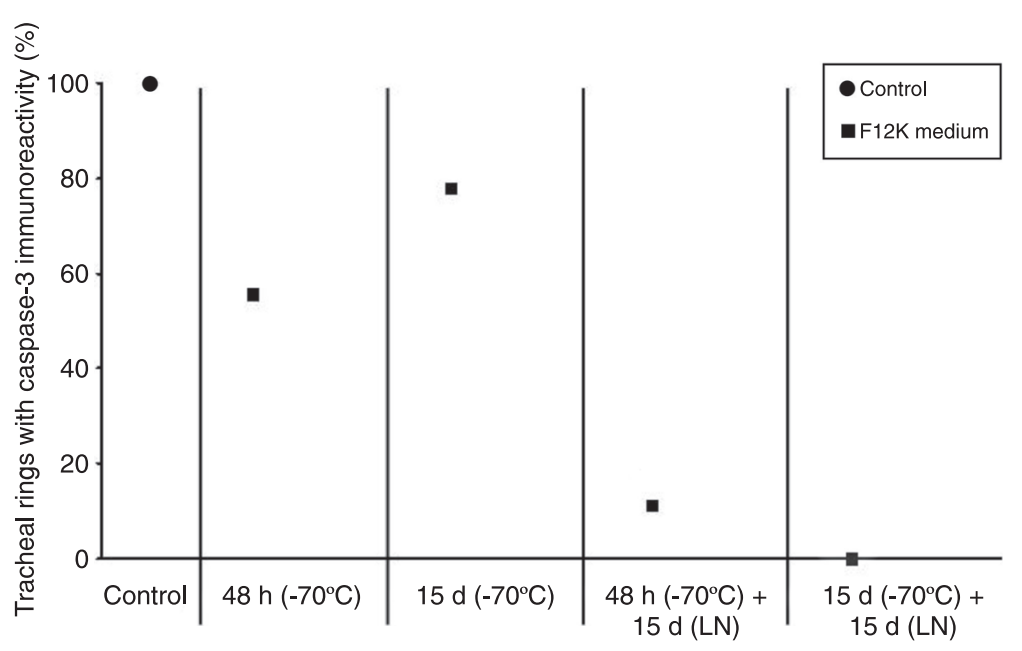

Figure 3. Percentage of the tracheal rings, which presented caspase- 3 immunoreactivity in tracheal mucosa epithelium. $d=$ days, $L N=$ liquid nitrogen. Caspase- 3 immunoreactivity decrease in the tracheal epithelium was statistically significant due to cryopreservation (control vs $-70^{\circ} \mathrm{C}$, control vs $-196^{\circ} \mathrm{C}$, and $-70^{\circ} \mathrm{C}$ vs $-196^{\circ} \mathrm{C}$; $\mathrm{P}<0.03$, ANOVA and Tukey test) regardless of storage time at $-70^{\circ} \mathrm{C}$ : (control, 2 days and 15 days at $-70^{\circ} \mathrm{C}$ vs 2 days and 15 days in $\mathrm{LN} ; \mathrm{P}=0.00$, ANOVA and Tukey test).
Tracheal mixed glands. The number and percentage of tracheal rings with caspase-3 immunoreactivity in mixed glands are shown in Table 2 and are illustrated in Figure 6.

All 18 rings $(100 \%)$ of the tracheal mixed glands from the control group presented caspase-3 immunoreactivity. Inside every ring there were areas with different caspase-3 immunoreactivity, which were classified as follows: 1) mixed glands without caspase-3 immunoreactivity, 2) caspase-3 in the demilunes of the mixed glands without involved epithelium, 3) caspase-3 in the demilunes of the mixed glands with moderately involved epithelium, and 4) caspase- 3 in the demilunes of the mixed glands with seriously involved epithelium (Figure 7).

The mixed glands in the cryopreserved groups presented decreased caspase- 3 immunoreactivity (Figure 8). The percentage of tracheal rings with caspase- 3 immunoreactivity in the mixed glands of cryopreserved groups was $83.3 \%$ for group 2, $22.2 \%$ for group 3, $72.2 \%$ for group 4 , and $16.7 \%$ for group 5.

All cryopreserved groups showed a decreased number of rings with caspase-3 immunoreactivity in the tracheal mixed glands compared to control. This decrease was statistically significant in the groups cryopreserved at a lower temperature $\left(-196^{\circ} \mathrm{C}\right)$ (control and $-70^{\circ} \mathrm{C}$ vs $-70^{\circ} \mathrm{C}+$ liquid nitrogen; $\mathrm{P}=0.00$, ANOVA and Tukey test), with no significant difference between the number of rings with caspase- 3 immunoreactivity in the tracheal mixed glands due to the freezing effect at $-70^{\circ} \mathrm{C}$ (control vs

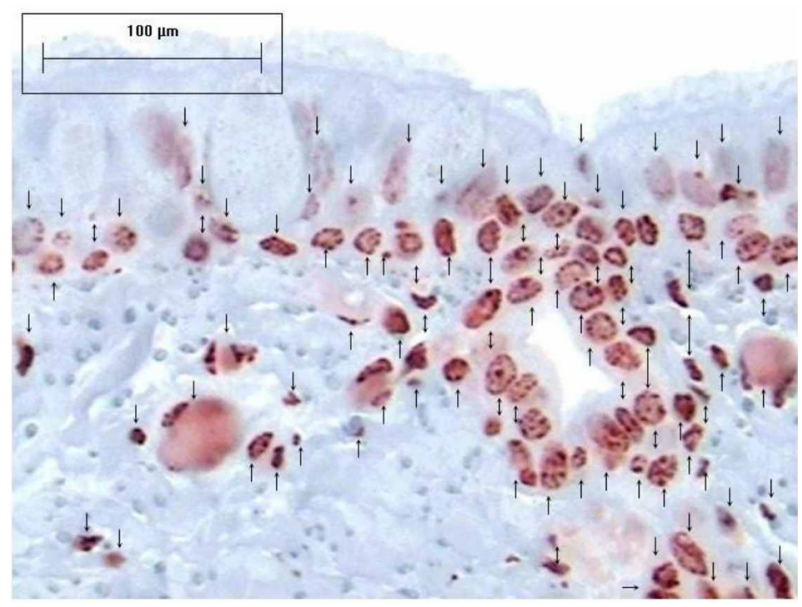

Figure 4. Tracheal mucosa from the control group without cryopreservation, with caspase-3 immunoreactivity present in most of the epithelial cells (AEC-hematoxylin, 40X). Arrows point out cells with caspase- 3 immunoreactivity.

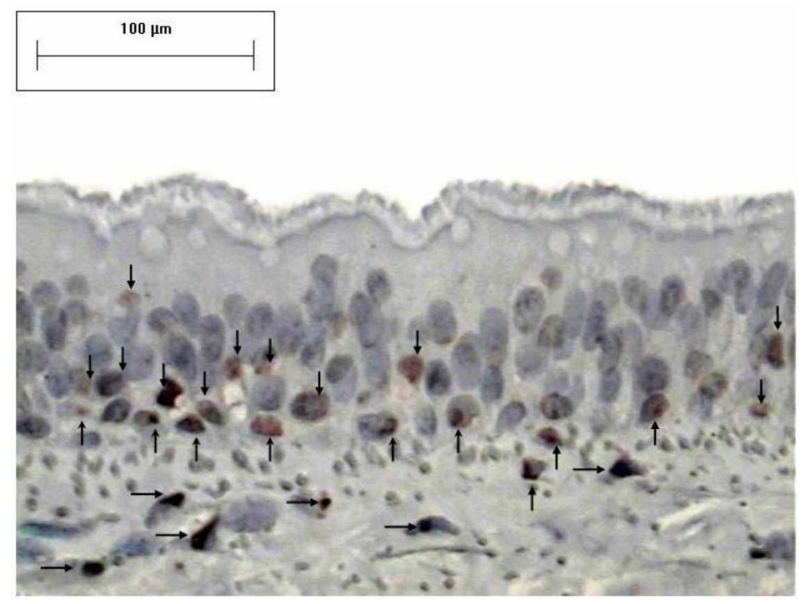

Figure 5. Caspase-3 immunoreactivity in the epithelium from cryopreserved tracheal grafts (AEC-hematoxylin, 40X). Arrows point out cells with caspase- 3 immunoreactivity. 
Table 2. Study groups, cryopreservation conditions, and number and percentage of tracheal rings with caspase-3 immunoreactivity in the glands.

\begin{tabular}{ccccc}
\hline Groups & $\begin{array}{c}\text { Cryopreservation } \\
\text { time }\left(-70^{\circ} \mathrm{C}\right)\end{array}$ & $\begin{array}{c}\text { Storage in liquid } \\
\text { nitrogen (15 days) }\end{array}$ & $\begin{array}{c}\text { Rings with mixed gland } \\
\text { caspase-3 immunoreactivity }\end{array}$ & $\begin{array}{c}\text { Rings without mixed gland } \\
\text { caspase-3 immunoreactivity }\end{array}$ \\
\hline 1 & - & - & $18(100 \%)$ & $0(0 \%)$ \\
2 & 2 days & No & $15(83.3 \%)$ & $3(16.7 \%)$ \\
3 & 2 days & Yes & $4(22.2 \%)$ & $14(77.8 \%)$ \\
4 & 15 days & No & $13(72.2 \%)$ & $5(27.8 \%)$ \\
5 & 15 days & Yes & $3(16.7 \%)$ & $15(83.3 \%)$ \\
\hline
\end{tabular}

Data are reported as number with percent in parentheses for 18 rings.

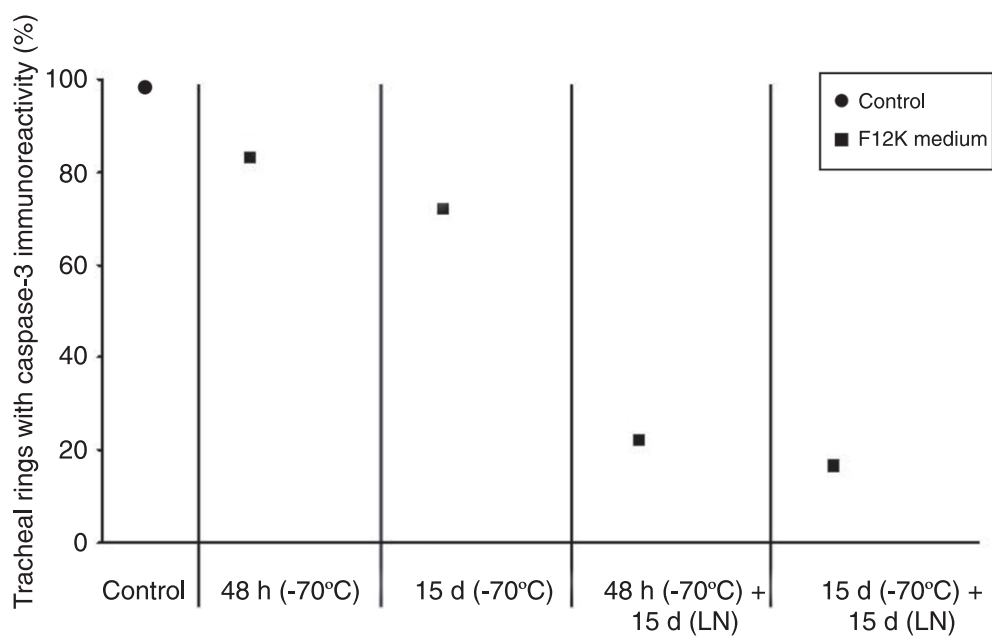

Figure 6. Study groups, cryopreservation conditions and percentage of tracheal rings, which presented caspase-3 immunoreactivity in the glands. $d=$ days, $L N=$ liquid nitrogen. Caspase- 3 immunoreactivity decrease in the tracheal mixed glands was statistically significant due to storage of treacheal segments in $\mathrm{LN}$ (control and $-70^{\circ} \mathrm{C} v s-70^{\circ} \mathrm{C}+\mathrm{LN} ; \mathrm{P}=0.00$, ANOVA and Tukey test).

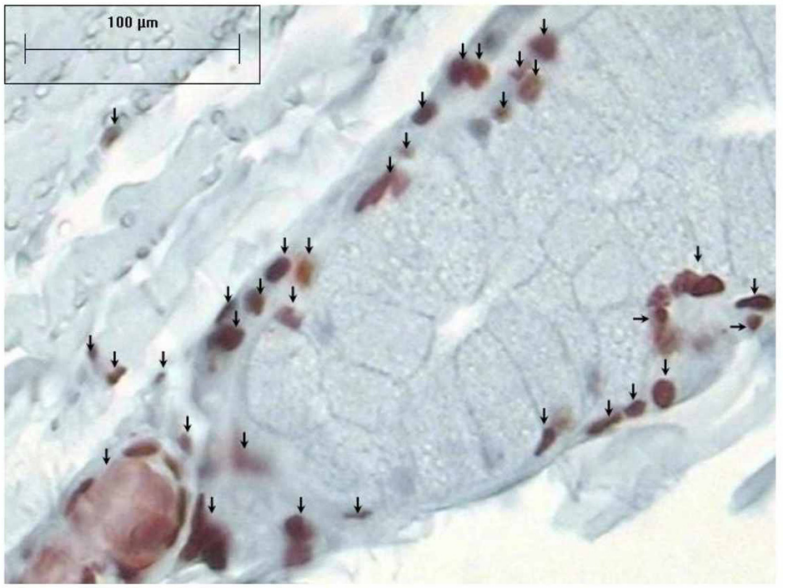

Figure 7. Caspase-3 immunoreactivity in tracheal mixed glands with severe epithelial involvement (AEC-hematoxylin, 40X). Arrows point out cells with caspase- 3 immunoreactivity.

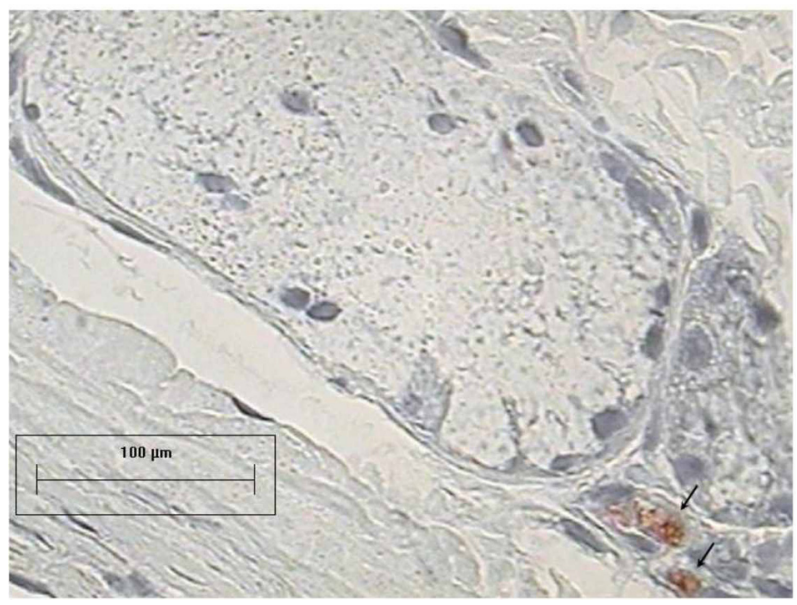

Figure 8. Tracheal glands with depletion of structural integrity and caspase- 3 immunoreactivity from cryopreservation groups (AEC-hematoxylin, 40X). Arrows point out cells with caspase-3 immunoreactivity. 
$-70^{\circ} \mathrm{C} ; \mathrm{P}=0.10$, ANOVA and Tukey test), and in the groups stored in liquid nitrogen for 15 days, regardless of prior freezing time at $-70^{\circ} \mathrm{C}$ (control, 2 days at $-70^{\circ} \mathrm{C}$ and 15 days at $-70^{\circ} \mathrm{C}$ vs 2 days +15 days in liquid nitrogen and $v s$ 15 days +15 days in liquid nitrogen; $P<0.01$, ANOVA and Tukey test). No significant difference was found between the number of rings with caspase- 3 immunoreactivity in the tracheal mixed glands of the groups cryopreserved at $-70^{\circ} \mathrm{C}$ (control without cryopreservation vs 2 days, $\mathrm{P}=0.66$; control vs 15 days, $\mathrm{P}=0.17 ; 2$ days vs 15 days, $\mathrm{P}=0.89$; 2 days vs 15 days (after liquid nitrogen storage), $\mathrm{P}=0.99$, ANOVA and Tukey test).

\section{Discussion}

We evaluated caspase-3 immunoreactivity in the remaining epithelium of tracheal grafts cryopreserved with $\mathrm{F} 12 \mathrm{~K}$ medium at $-70^{\circ} \mathrm{C}$, with or without subsequent storage in liquid nitrogen. Cryopreservation involves the benefit of hypothermia, which prevents ischemic injury and reduces cell metabolism, although the process itself is not innocuous. Different methods and protocols are used to cryopreserve cells or tissues with different cryopreservation solutions. The main goal of cryopreservation solution is to nourish cells at physiological and low temperatures to keep cell viability. They also contain concentrations of electrolytes similar to normal intracellular levels, in order to restrict the ischemic imbalances as a result of reduced temperature and the switching off of ionic pumps. They also have an impermeant anion to reduce cellular swelling during low temperature storage. The F12K nutrient medium has been used successfully in tissue engineering and in articular chondrocyte and tracheal cryopreservation. Thus, we thought that it could be very useful for the present investigation since our goal was to study the effects of cryopreservation and apoptosis on the tracheal epithelial cells, limiting damage to the tracheal cartilage. We added $20 \%$ SBF and $10 \%$ DMSO cryoprotective agents to the $\mathrm{F} 12 \mathrm{~K}$ nutrient solution in order to limit cryoinjury.

There are many reports about tracheal cryopreservation time (1 to 730 days). However, better cell viability has been reported after shorter periods of cryopreservation, since tracheal cartilage is prone to severe damage with a long cryopreservation time. Our aim in the present investigation was to study the viability of tracheal epithelial cells remaining after cryopreservation and its apoptotic process, since these are the most powerful antigenic fac-

\section{References}

1. Fuchs JR, Nasseri BA, Vacanti JP. Tissue engineering: a 21 st century solution to surgical reconstruction. Ann Thorac Surg 2001; 72: 577-591.

2. Sakata J, Vacanti CA, Schloo B, Healy GB, Langer R, Vacanti JP. Tracheal composites tissue engineered from chon- tors $(3,6,11,29)$; however, tracheal cartilage viability and structure must be kept as viable as possible, since they provide the framework for tracheal transplantation. Thus, we also wanted to obtain the best viability of tracheal cartilage (knowing that we would get some degree of epithelial cell viability). The best cryopreservation times are between 2 and 15 days and traditionally thawing time is short (1-3 $\mathrm{min}$ ) at $37-40^{\circ} \mathrm{C}$ for cells cryopreserved in $1-2 \mathrm{~mL}$ vials. In the present study, we decided to increase thawing time to $30 \mathrm{~min}$ at $37^{\circ} \mathrm{C}$ since a 5 -ring segment needs $25 \mathrm{~mL}$ of cryopreservation solution. In our experience working with trachea cryopreservation, we have observed that a short thawing time results in non-homogeneous defrosting, since cryopreservation solution defrosting begins from the outside, with the intraluminal tracheal cryopreservation solution being the last to defrost.

The apoptotic process of different cellular groups begins with harvesting and continues during cryopreservation and cell thawing, triggering caspase-3 (33-35). We found a greater quantity of tracheal epithelial and mixed glands and higher caspase-3 immunoreactivity in the control group (without cryopreservation) than in the cryopreserved groups, which showed fewer numbers of tracheal epithelial cells and mixed glands, with a consequent reduction of caspase- 3 immunoreactivity $(P<0.03$, ANOVA and Tukey test) mainly in the liquid nitrogen groups. Histologically, there is an important loss of cell viability. Thus, the decrease in caspase- 3 immunoreactivity can be explained by increased cell death rather than by biochemical changes within the cell. Increased caspase-3 immunoreactivity in the epithelium and tracheal glands after harvesting of the control group could be explained by two different etiologies, i.e., ischemia from surgical dissection and tissue damage due to mechanical ventilation that increases caspase-3 immunoreactivity (36).

We have shown that apoptosis can be triggered in epithelial cells during tracheal graft harvesting even prior to cryopreservation, and although epithelial caspase-3 immunoreactivity is reduced, in tracheal cryopreservation this could be explained by increased cell death. We can hypothesize that epithelial apoptosis can be present during tracheal graft harvesting, even before cryopreservation. Thus, antiapoptotic agents would decrease cellular death due to apoptosis during graft harvesting, with a subsequent higher caspase-3 immunoreactivity in the remaining epithelium due to the cryopreservation effect. 
portunity for tracheal tissue banking. Transplant Proc 2001; 33: 609-611.

4. Zhao H, Hua TC, Zhou YZ, Wang QF, Yang Y, Bao LL. Cryopreservation and transplantation of dog trachea. Ann N Y Acad Sci 1998; 858: 270-275.

5. Murakawa T, Nakajima J, Motomura N, Murakami A, Takamoto S. Successful allotransplantation of cryopreserved tracheal grafts with preservation of the pars membranacea in nonhuman primates. J Thorac Cardiovasc Surg 2002; 123: 153-160.

6. Sotres-Vega A, Villalba-Caloca J, Jasso-Victoria R, OlmosZuniga JR, Gaxiola-Gaxiola M, Baltazares-Lipp M, et al. Cryopreserved tracheal grafts: a review of the literature. $J$ Invest Surg 2006; 19: 125-135.

7. Tojo T, Niwaya K, Sawabata N, Kushibe K, Nezu K, Taniguchi $\mathrm{S}$, et al. Tracheal replacement with cryopreserved tracheal allograft: experiment in dogs. Ann Thorac Surg 1998; 66: 209-213.

8. Lenot B, Macchiarini P, Dulmet E, Weiss M, Dartevelle P. Tracheal allograft replacement. An unsuccessful method. Eur J Cardiothorac Surg 1993; 7: 648-652.

9. Tojo T, Niwaya K, Sawabata N, Nezu K, Kawachi K, Kitamura $\mathrm{S}$. Tracheal allogenic immunoresponse is reduced by cryopreservation: canine experiment. Transplant Proc 1996; 28: 1814-1815.

10. Moriyama H, Sasajima T, Hirata S, Yamazaki K, Yatsuyanagi E, Kubo Y. Revascularization of canine cryopreserved tracheal allografts. Ann Thorac Surg 2000; 69: 1701-1706.

11. Kushibe K, Nezu K, Nishizaki K, Takahama M, Taniguchi S. Tracheal allotransplantation maintaining cartilage viability with long-term cryopreserved allografts. Ann Thorac Surg 2001; 71: 1666-1669.

12. Nakanishi $R$, Onitsuka $T$, Shigematsu $Y$, Hashimoto $M$, Muranaka $\mathrm{H}$, Yasumoto $\mathrm{K}$. The immunomodulatory effect of cryopreservation in rat tracheal allotransplantation. $J$ Heart Lung Transplant 2002; 21: 890-898.

13. Nakanishi $R$, Umesue $M$, Hashimoto $M$, Muranaka $H$, Hachida M, Yasumoto K. Limit of warm ischemia time before cryopreservation in rat tracheal isografts. Ann Thorac Surg 2000; 70: 1880-1884.

14. Nakanishi R, Hashimoto M, Muranaka H, Yasumoto K. Effect of cryopreservation period on rat tracheal allografts. $J$ Heart Lung Transplant 2001; 20: 1010-1015.

15. Kushibe K, Tojo T, Sakaguchi H, Takahama M, Nezu K, Taniguchi $\mathrm{S}$, et al. Assessment of cartilage viability in the cryopreserved tracheal allograft by measurement of $\mathrm{Na}_{2}{ }^{35} \mathrm{SO}_{4}$ incorporation. Transplant Proc 2000; 32: 1655-1656.

16. Hashimoto M, Nakanishi R, Umesue M, Muranaka H, Hachida M, Yasumoto K. Feasibility of cryopreserved tracheal xenotransplants with the use of short-course immunosuppression. J Thorac Cardiovasc Surg 2001; 121: 241-248.

17. Kushibe K, Takahama M, Nezu K, Taniguchi S. Assessment of cartilage viability in long-term cryopreserved tracheal allografts. Transplant Proc 2001; 33: 625-626.

18. Kushibe K, Tojo T, Sakaguchi H, Takahama M, Nishizaki K, Nezu K, et al. Effects of warm ischemia and cryopreservation on cartilage viability of tracheal allografts. Ann Thorac Surg 2000; 70: 1876-1879.

19. Deschamps C, Trastek VF, Ferguson JL, Martin WJ, Colby TV, Pairolero PC, et al. Cryopreservation of canine trachea: functional and histological changes. Ann Thorac Surg 1989; 47: 208-212.
20. Messineo A, Filler RM, Bahoric A, Smith CR. Repair of long tracheal defects with cryopreserved cartilaginous allografts. J Pediatr Surg 1992; 27: 1131-1134.

21. Inutsuka K, Kawahara K, Takachi T, Okabayashi K, Shiraishi T, Shirakusa T. Reconstruction of trachea and carina with immediate or cryopreserved allografts in dogs. Ann Thorac Surg 1996; 62: 1480-1484.

22. Yokomise H, Inui K, Wada H, Ueda M, Hitomi S. Tracheal transplantation in dogs for future clinical application. Transplant Proc 1996; 28: 1763-1764.

23. Nakanishi R, Hashimoto M, Muranaka H, Umesue M, Kohno $\mathrm{H}$, Yasumoto K. Maximal period of cryopreservation with the Bicell biofreezing vessel for rat tracheal isografts. J Thorac Cardiovasc Surg 1999; 117: 1070-1076.

24. Mukaida T, Shimizu N, Aoe M, Andou A, Date H. Tracheal allotransplantation after varying terms of cryopreservation. Transplant Proc 1998; 30: 3397-3400.

25. Kunachak S, Kulapaditharom B, Vajaradul Y, Rochanawutanon M. Cryopreserved, irradiated tracheal homograft transplantation for laryngotracheal reconstruction in human beings. Otolaryngol Head Neck Surg 2000; 122: 911-916.

26. Yokomise $\mathrm{H}$, Inui K, Wada H, Ueda M, Hitomi S. Long-term cryopreservation can prevent rejection of canine tracheal allografts with preservation of graft viability. J Thorac Cardiovasc Surg 1996; 111: 930-934.

27. Mukaida T, Shimizu N, Aoe M, Andou A, Date H, Okabe K, et al. Experimental study of tracheal allotransplantation with cryopreserved grafts. J Thorac Cardiovasc Surg 1998; 116: 262-266.

28. Liu Y, Zheng R, Ding J, Qiao Y, Wang Q. Histological examination of cryopreserved rat tracheal grafts. ASAIO J 2007; 53: 492-496.

29. Aoki T, Yamato Y, Tsuchida M, Souma T, Yoshiya K, Watanabe $\mathrm{T}$, et al. Successful tracheal transplantation using cryopreserved allografts in a rat model. Eur J Cardiothorac Surg 1999; 16: 169-173.

30. Elmore S. Apoptosis: a review of programmed cell death. Toxicol Pathol 2007; 35: 495-516.

31. Diario Oficial de la Federación. Especificaciones técnicas para la producción, cuidado y uso de animales de laboratorio de la Norma Oficial Mexicana NOM-062-ZOO-1999. Mexico: Estados Unidos Mexicanos (diciembre 6); 1999.

32. U.S. Department of Health and Human Services. Guide for care and use of laboratory animals. Public Health Service, National Institutes of Health; 1985.

33. Stroh C, Cassens U, Samraj AK, Sibrowski W, Schulze-Osthoff K, Los M. The role of caspases in cryoinjury: caspase inhibition strongly improves the recovery of cryopreserved hematopoietic and other cells. FASEB J 2002; 16: 16511653.

34. Yagi T, Hardin JA, Valenzuela YM, Miyoshi H, Gores GJ, Nyberg SL. Caspase inhibition reduces apoptotic death of cryopreserved porcine hepatocytes. Hepatology 2001; 33: $1432-1440$.

35. Xiao J, Zou P, Huang SA, Hu ZB, Liu LB, You Y. [Role of apoptosis in cryoinjury of cord blood hematopoietic stem/ progenitor cells and its mechanism]. Zhongguo Shi Yan Xue Ye Xue Za Zhi 2004; 12: 90-94.

36. Hu GD, Cai SX, Chen YH, Gao F. [Effect of different tidal volume ventilation on rat bronchial and alveolar epithelial cell apoptosis]. Di Yi Jun Yi Da Xue Xue Bao 2005; 25: 508512. 